\title{
Biochemical and Anthropometric Markers, Metabolic Syndrome and Main Dietary Habits of a Waraos Population Sample
}

\author{
Lares Mary $^{1,2^{*}}$, Pérez Elevina ${ }^{3}$, Schroeder Mileibys ${ }^{4,5}$, Gestne Aure $^{1}$, Case Cynthia ${ }^{1}$, Brito Sara ${ }^{1}$, \\ Ciarfella Ana ${ }^{6}$
}

\footnotetext{
${ }^{1}$ Departamento de Endocrinología y Enfermedades Metabólicas del Hospital Militar, Caracas, Venezuela; ${ }^{2}$ Escuela de Nutrición y Dietética, Facultad de Medicina, Universidad Central de Venezuela, Caracas, Venezuela; ${ }^{3}$ Instituto de Ciencia y Tecnología de Alimentos, Facultad de Ciencias, Universidad Central de Venezuela, Caracas, Venezuela; ${ }^{4}$ University of Phoenix, Human Service and Social Science Department, Yuma, Arizona; ${ }^{5}$ Mountain Health and Wellness (MHW) of Yuma, Yuma, Arizona; ${ }^{6}$ Universidad de Oriente Unidad de Cursos Básicos, Núcleo Anzoátegui, Puerto La Cruz, Venezuela.

Email: "marylares@hotmail.com
}

Received April $9^{\text {th }}, 2011$; revised May $9^{\text {th }}, 2011$; accepted May $16^{\text {th }}, 2011$.

\begin{abstract}
The goals of the research were to establish the biochemical and anthropometric markers of the Waraos sample population, its frequency of metabolic syndrome and through a survey, the mains components of its diet: Moriche fruit, plantain, cassava root and its products. A clinical study was including a population of 145 individuals belonging to the Yakariken community, Waraos tribe. From this group a random sample of 42 individuals was selected and anthropometric measurements, glucose and insulin in blood serum, insulin resistance by HOMA, blood pressure, as well as lipidic profile were tested. Additionally, samples of the Moriche fruit, plantain unripe fruit, "cassava" root and "casabe" (cake made from cassava edible pulp) were analyzed. The results obtained showed an average corporal mass index of $23.27 \pm$ 2.52 together with the waist average of $79.51 \pm 6.53$. The blood screen results demonstrated that in average the basal glucose content was $80.38 \pm 12.82 \mathrm{mg} / \mathrm{dl}$, the basal insulin $9.05 \pm 6.75$, mean of the blood pressure of $90 \pm 12, \mathrm{HOMA}$ $1.80 \pm 1.78$, total cholesterol $133.52 \pm 21.42 \mathrm{mg} / \mathrm{dl}$, HDL $37.22 \pm 7.88 \mathrm{mg} / \mathrm{dl}, \mathrm{LDL} 82.23 \pm 18.20$ and the triglycerides $105.12 \pm 62.56 \mathrm{mg} / \mathrm{dl}$. The fruits composition had shown high contents of dietary fiber (19.86\%), resistant starch (17.61\%) and crude fats (18.40\%). The results concluded that a diet rich in complex carbohydrates, fibers and unsaturated fatty acids, beside exercise should induce a low insulin resistance with the absence of dislipidemia, reducing the risk for the development of any metabolic syndrome. These results are inherent in low incidence of cardio vascular alterations.
\end{abstract}

Keywords: Moriche (Mauritia Flexuosa), Glicemic and Response, Waraos Tribe People

\section{Introduction}

Mauritia flexuosa trees from the Family palmae are grown extensively as palm trees that are rising up to 90 -feet tall in the savannas and swamps of the tropical Venezuelan forest of the Orinoco Delta. The Moriche palm is the common name given to the palm trees by the indigenous of Peruvian Amazonia area, and they can be found in a wide area that reaches the tropical extension between Bolivia up to Colombia and Venezuela. This palm tree is also labeled with the common name of aguajé, buriti palm, mauriti palm, ita palm, miriti, tree-of-live, Mauritia setigera, Mauritia sphaercarpa or
Mauritia vinifera. The fruit from the palm is a drupa (Figure 1(a)) with high fiber (41.9\%) and fat (49.1\%) contents [1]. More than $61 \%$ of this fat is of the unsaturated and healthy type with potential characteristics cardioprotective. Amazonian fruits (Mauritia flexuosa) also have high levels of tocopherols (vitamin E) [2]. Fruits from this palm tree are also a (potential) oil source, and it is often heavily exploited and commercially used [3]. Some reports also [4] had indicated that oils extracted from the fruit have potential pharmaceutical applications. Some researchers have $[2,5]$ shown that the content of fatty acids in the pulp of the Moriche palm fruit are: 


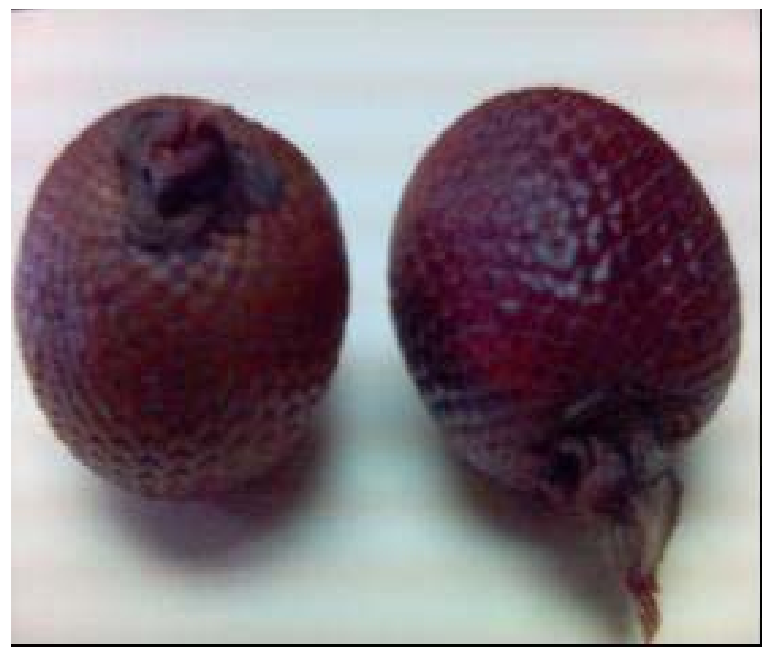

(a)

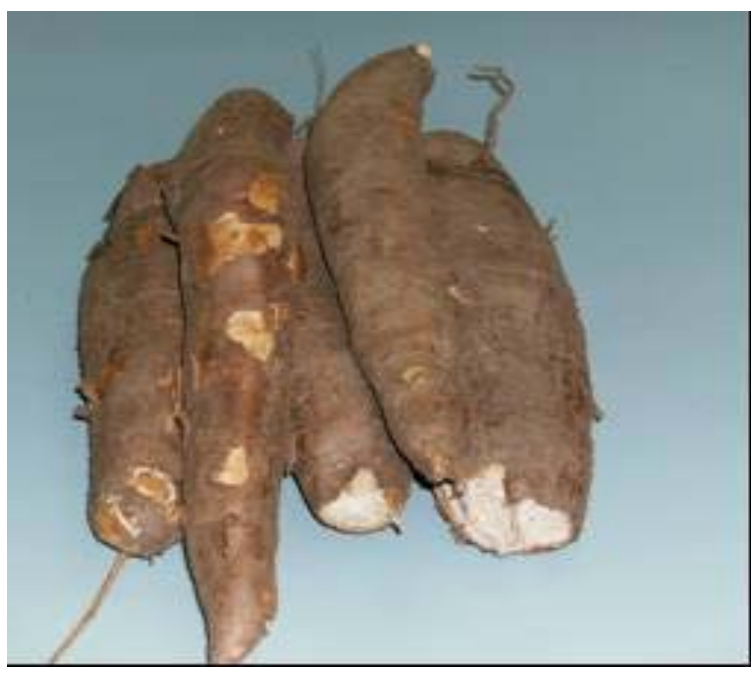

(c)

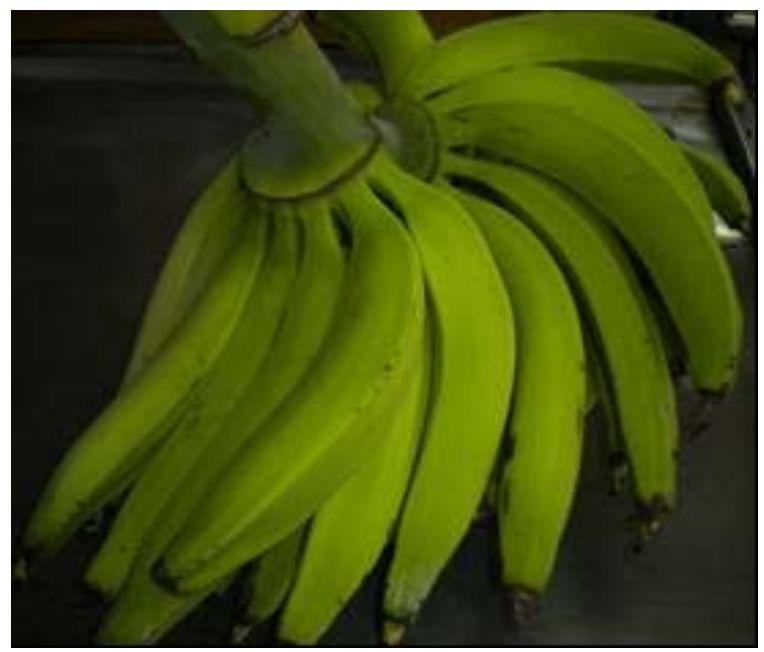

(b)

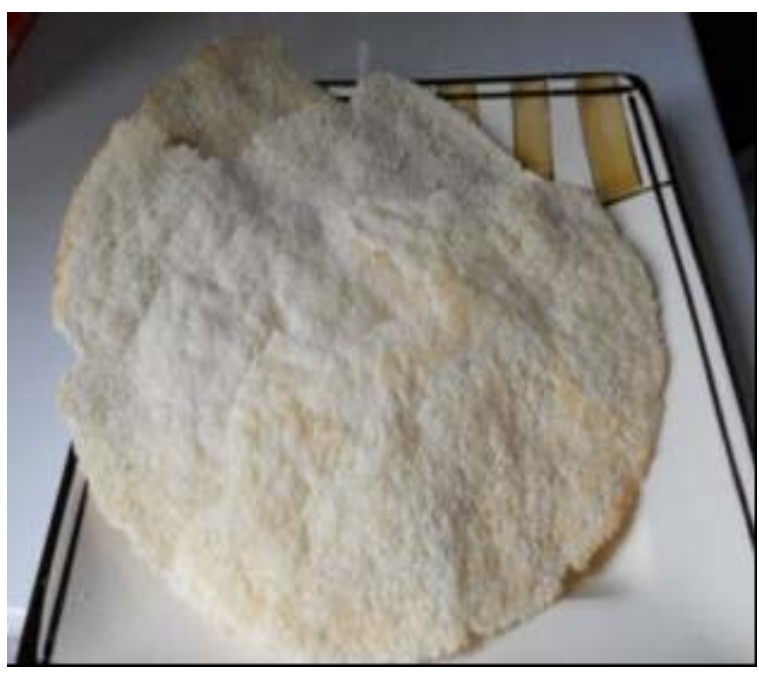

(d)

Figure 1. (a) Palm Moriche (Mauritia flexuosa) fruits, (b) plantain (Musa paradisiaca L.) Var. Harton Comun fruit, (c) cassava (Manihot esculenta crantz) root, and (d) “casabe” cake.

$78.3 \%$ oleic acid, $18 \%$ palmitic acid, $2.7 \%$ linoleic acid, $0.7 \%$ linolenic acid, and other minor components such as $0.2 \%$ estearic acid and $0.1 \%$ palmitoleic acid.

Musa paradisiaca L., comprising banana and plantain (Figure 1(b)) are among the world's leading fruit crop. Plantain and unripe banana are consumed cooked, whereas, mature dessert banana is eaten raw. According to the USDA database and other recent source [6], bananas are the starchy staple with the highest potassium and low sodium content. Bananas are also recognized by its low digestibility, because of its highest resistant starch content [7]. Resistant starch is considered as dietary fiber because it can have benefits of insoluble fiber and some benefits of soluble fiber. The resistant starch lowers the glycemic and insulin impact of foods [8,9].

The roots of cassava (Manihot esculenta crantz) (Figure 1(c)) are also cultivated and consumed in great deal in the Amazonia tropical and subtropical areas they are a main source of calories, due to its high contents of carbohydrates. "casabe" or flours are important side dishes elaborated from the cassava root, providing a high content of dietary fiber and resistant starch [10]. Fiber reduces the absorption of cholesterol in the diet, and it also slows down the rate of absorption of sugars from the food in the digestive system. Certain types of fiber increase the viscosity of the food content. This increased viscosity indirectly reduces the need for insulin secreted by the pancreas. From consensus, dietary fiber has three physiological effects: Fecal bulking and colonic effects 
related to fermentation, 2-lowering of postprandial blood glucose response and lowering of plasma (LDL) cholesterol [11]. Thus a fiber-rich diet can help minimizing metabolic syndromes.

The Waraos ethnic group inhabits the area associated with the Orinoco River delta to which they are used to, exhibiting a typical lifestyle that is particularly nonsedentary. As expected a large part of the activities displayed by the Waraos includes the gathering of the staple foodstuff that constitute their diet. Today despite the Waraos possessing a traditional economic system based on fishing and hunting, and maintaining plantations of taro, cassava, banana, maize and rice, the Moriche palm or OJIRU (tree of life) is the most important species of wild resources offered [12].

The fruit of the Moriches Palm tree has been previously established as an important part of the diet, typically consumed by the Waraos tribe, which is indigenous to the Orinoco River Delta. The abundant presence of Moriches fruit in the Waraoss diet, together with plantain, cassava and fish (for protein) intake, beside their nomad condition does induce a low glucose and lipid basal within the population.

Regional differences in food and culture have left their mark on human been genome. Around the world, populations have adapted to their diet to make the most of local resources. In some instances, foodstuffs can protect against deadly infection, giving selective advantage to those who can readily digest it [13].

The objectives of this research were to establish the biochemical and anthropometric markers, the frequency of metabolic syndrome of the Waraos sample population and to analyze the composition of the some of the main vegetable foods of the Waraos diet: Moriche palm fruits, banana fruits and the cassava products. The sample was the adult population ( 20 - 55 years old) of a typical Waraos settlement of both genders.

\section{Materials and Methods}

\subsection{Sample Sources}

Random sample batches of plantains, palm Moriche (Mauritia flexuosa) fruits and cassava roots were harvested from the farm of the Waraos population and was brought to the lab for further analysis. The "casabe" cake samples were also brought from the Waraos traditional cooking practices. After harvesting, roots were peeled, soaked and grated, squeezed, sifted, and the glucocyanogens lixiviate with the use of a press. The pulp was passed through a sieve to obtain fine flour and placed on a hot plate (budare). Finally, once cooked, the "casabe" cake produced was sun-dried.

\subsection{Population Sampling}

The study was performed in a six months period within the population of 145 adults from the Yakariken rural community of the rain forest of the Delta Amacuro state, Venezuela, and estimating random samples of 42 individuals. The selected group of study included 29 female and 13 male adults, comprising an age range from 20 to 55 years old. Each individual of the study group completed a supervised interview, and also were assessed to identify any relevant habit that could affect the result, such as eating habits, specific physical activity and tabaquism. Additionally, the corporeal mass index (IMC), waist circumference (MCC), glucose and insulin basal measurement, and insulin resistance by HOMA were quantified. Moreover, the basal lipidic profile (choles- terol, triglycerides, HDL-C and LDL-C) and blood pressure were measured [14]. The proximate and nutriational composition upon samples of the Moriche fruit, plantain unripe fruit, cassava root and "casabe" cake were tested as well.

\subsection{Laboratory Analysis}

To perform the necessary blood measurements, samples were taken after 14 hours of feasting and were centrifuged at $1000 \mathrm{~g}$ up to 20 minutes. The specified analysis was carried by standard methods. The glucose, cholesterol, Triglycerides and HDL cholesterol tests were performed via commercial enzymatic kit manufactured by Roche. The LDL cholesterol content was assessed by means of the Friewald formula and the insulin content was determined by means of the electro-quimico-luminescence method ECLIA. Insulinic sensibility was estimated using the Homeostasis Model, expressed by the following formula: HOMA-R = Insulin $(\mathrm{mu} / \mathrm{ml}) *$ Glucose $(\mathrm{mmol} / \mathrm{L}) / 22.5$ [15].

Moisture, crude protein, crude fat, ash, dietary, crude fiber, and resistant starch contents were the analysis performed on the fruits, roots and "casabe" samples. These were carried out according to the methods de- scribed by the AOCI, AACC and Goñi et al. [16-18]. The total carbohydrate content was calculated by difference [19].

\subsection{Statistical Analysis}

The results reported in the tables describe the average and the standard deviation values calculated from the individual measurements.

\section{Results and Discussion}

The available literature [20-22] suggested that typical obesity is associated with individuals who show a corporal mass index (IMC) greater than $\geq 25(\mathrm{OWH})$. When 
compared with the IMC values obtained from the study of the Waraos population sample, (see Table 1), the in- dex is significantly lower among both males and females, congruently acceptable with the literature $[23,24]$ of the IMC of 19 to 25 . This is consistent with the results obtained from the insulin resistance as expressed by the HOMA model, shown in Table 1, for the population studied. The resulting average value for both sex groups is of 1.80 , which it is a low resistance index value. Another aspect that is closely linked to the nutritional scheme followed by the Waraos sample studied was re- flected by the basal lipid obtained, which is shown in Table 1. As can be noticed the average content for both sexes are as follows: cholesterol $133.52 \mathrm{mg} / \mathrm{dl}$, HDL $37.22 \mathrm{mg} / \mathrm{dl}$, LDL $82.23 \mathrm{mg} / \mathrm{dl}$ and triglycerides at $105.12 \mathrm{mg} / \mathrm{dl}$, these results agree with those shown in literature [22]. These values can be considered within the context of the observed nutritional scheme followed by the population studied because the supervised interviews carried out revealed that a large portion of the caloric intake was related to the ingestion of the Moriche palm, banana fruits and cassava products in various forms. As can be seen these foods have high dietary fiber, resistant starch, and fat contents. As reported previously [11] the resistant starch and the fiber have been associated with a diminution of the cholesterol level, and also low insulin resistant.

The nutritional analysis performed on the samples of the Moriche palm, banana fruits and cassava products revealed that the total carbohydrate and fiber content was high, varying from $3.23 \%$ for cassava flour to $19.86 \%$ plantain unripe $(\mathrm{db})$, and the resistant starch was quite high for plantain: 17.61\% (Table 2). The low value of resistant starch shown by the cassava root is comparable with those reported by literature to roots from cooked cassava, and yam tubers cultivated in Costa Rica [25]. All samples have shown quite low crude fat contents, except for the Moriche fruits. However, this fruits have an excellent fatty acids profile [2]. Other important factor is that the bananas have the highest potassium and lowest sodium content as reported by Gibert et al. [6].

All of these results could be associated with specific glucose basal observed from the Waraos population
Table 1. Anthropometric and biochemical markers of the Waraos population $(n=42)$.

\begin{tabular}{lc}
\hline Parameters & Values \\
\hline Body mass index $\left(\mathrm{kg} / \mathrm{m}^{2}\right)$ & $23.27 \pm 2.52$ \\
Waist circumference $\left(\mathrm{cm}^{2}\right)$ & $79.51 \pm 6.53$ \\
Cholesterol total $(\mathrm{mg} / \mathrm{dl})$ & $133.52 \pm 21.42$ \\
HDL $(\mathrm{mg} / \mathrm{dl})$ & $37.22 \pm 7.88$ \\
LDL (mg/dl) & $82.23 \pm 18.20$ \\
Triglycerides $(\mathrm{mg} / \mathrm{dl})$ & $105.12 \pm 62.56$ \\
Blood Glucose (mg/dl) & $80.38 \pm 12.82$ \\
Insulin (mu/ml) & $9.05 \pm 6.75$ \\
HOMA & $1.80 \pm 1.78$ \\
Mean Blood Pressure $(\mathrm{mmHg})$ & $90.0 \pm 12.00$ \\
\hline
\end{tabular}

Values are reported as mean and standard deviation.

sample studied. However, for a conclusive link to be established, a measurement of the dietetic fiber and resistant starch content in the moriche fruits edible pulp must be performed. This is relevant because these aspects are directly associated with cholesterol content in the blood and the delay in glucose absorption [26]. The fatty acids content of Moriche fruits is also expected to bear an impact on the lipidic profile observed for the Waraos population. Even though this particular measurement was not performed in this study, it is reported in the literature that the fruit has high concentration of oleic acid [5]. This particular fatty acid (oleic) has shown not to exhibit statistical significant effects upon the reduction of both the total cholesterol and the LDL levels. However, the literature reveals that the substitution of polyunsaturated fatty acids, such as the linoleic and oleic, present a moderate reductive effect upon the cholesterol levels [27]. Therefore the substitution of saturated fatty acids by unsaturated acids such as the linoleic and oleic can be associated with the reduction of the cholesterol levels in the serum. This also can be accessed from the predictive model equations, which clearly suggested that the cholesterol content is associated to the change from saturated to unsaturated fatty acids [28]. A further explanation of the lipids basal can be achieved if the complimentary elements of the diet are considered. In this aspect the supervised interviews revealed that the consumption of fish, found on the local rivers, form the other important part of the diet followed by the Waraos population

Table 2. Proximate and nutritional composition of the fruits of Moriche (Mauritia flexuosa), cassava roots, “casabe” cake, plantain unripe, and banana ripe.

\begin{tabular}{|c|c|c|c|c|c|c|c|c|}
\hline & $\begin{array}{l}\text { Moisture } \\
(\%)\end{array}$ & $\begin{array}{l}\text { Crude Protein } \\
(\%)\end{array}$ & $\begin{array}{l}\text { Crude Fats } \\
(\%)\end{array}$ & $\begin{array}{l}\text { Carbohydrates } \\
(\%)\end{array}$ & $\begin{array}{l}\text { Carbohydrates } \\
\text { Available (\%) }\end{array}$ & $\begin{array}{l}\text { Resistant } \\
\text { starch (\%) }\end{array}$ & Fiber (\%) & $\begin{array}{l}\text { Ash } \\
(\text { mineral) (\%) }\end{array}$ \\
\hline Moriche Fruit & $43.16 \pm 0.94$ & $4.18 \pm 0.13$ & $18.40 \pm 0.19$ & $21.39 \pm 0.91$ & NA & NA & $12.32 \pm 0.20^{*}$ & $0.54 \pm 0.02$ \\
\hline Cassava Roots & $60.78 \pm 0.30$ & $0.70 \pm 0.24$ & $0.09 \pm 0.00$ & $36.10 \pm 0.65$ & $32.87 \pm 1.96$ & $0.7 \pm 0.02$ & $3.23 \pm 0.22^{* *}$ & $0.93 \pm 0.10$ \\
\hline "Casabe" Cake & $12.97 \pm 0,31$ & $1.36 \pm 0.03$ & $0.28 \pm 0.02$ & $83.7+0.00$ & $69.35 \pm 1.31$ & $3.79+0.25$ & $14.3 \pm 1.30^{* *}$ & $1.69 \pm 0.04$ \\
\hline Unripe Plantain & $60.3 \pm 0.95$ & $1.63 \pm 0.23$ & $0.24 \pm 0.06$ & $35.77 \pm 0.87$ & $33.52 \pm 0.87$ & $17.61 \pm 1.07$ & $19.86 \pm 0.00^{* *}$ & $0.96 \pm 0.06$ \\
\hline Ripe Banana $^{* * *}$ & $73.8^{*}$ & 1.0 & 1.3 & 23.2 & 19.8 & NA & 3.4 & 0.7 \\
\hline
\end{tabular}

Parameters are reported as mean and standard deviation; ${ }^{*}$ Crude, ${ }^{* *}$ Dietary, ${ }^{* * *}$ Source INN, 2001. 
studies. This element of their diet is known to have significant contents of eicopentanoic acid (EPA) as well as docohexanoic acid (ADH) [29,30].

Waraos are the oldest human group of Venezuela, believing his presence in its ancestral habitat, the Orinoco Delta, from about 8000 or 9000 years ago [31]. They have been mainly fishermen, as its main activity of subsistence, to lesser extent hunters, gatherers of honey and wild fruits, and it is a population that is characterized by low presence of cardiovascular disease. [31]

Genetics studies have pointed out that the Waraos group has a male haplotype QM3. The Waraos origin it is probably from Central Asia by the Altai Mountain. The Q haplogroups from the same region migrated to America, where its variants (Q1a3a (M3)) frequently are found in the "amerindios" [32] A new analysis of the genome published in 2011, argues that the expressions of a particular genes was due to the interrelation among susceptibility innate, diet and life style factors. [33]

The Waraos ethnic group demonstrated a low incidence of cardiovascular disease, with low values of LDL-cholesterol and a metabolic syndrome frequency of 2.38. However they also have low HDL-cholesterol, particles with atero-protection, whose high values are in inverse relationship to coronary arterial disease for any value of LDL [34]

Recent studies have shown prevalence of atherosclerosis in certain individuals with increases in the circulating levels of HDL. The studies have raised the new concept of dysfunctional HDL, which defines an HDL that although this represented by high concentrations in plasma had lost their protective actions [35]. Compatibly to these populations there are those whose ethnic origins descent are from the west and that particularly have high incidence of cardiovascular disease, and metabolic syndrome. These ethnic groups are presenting low HDL, but without hypertriglyceridemia, considering that it could never be isolated the HDL low as criterion of the prevalence of metabolic syndrome. In other words, the hypertriglyceridemia shows resistance on the presence of insulin. The decrease in lipoprotein lipase activity with increase activity of lipase hepatica is a common mechanism to explain this combination. These ethnic groups, as the Waraos, present low HDL in the absence of other features of the metabolic syndrome. Walker and Walker (1970) [36] have indicated from their studies in Africathat those values between 60 and $70 \mathrm{mg} / \mathrm{dl}$ have undergone decrease up to $35 \mathrm{mg} / \mathrm{dl}$ of HDL, when they were described in 2006 [37]. The authors pointed out that this diminution could be attributed to the urbanization in Africa, contrary to the Waraos population, whom has retained its natural habitat [36].

\section{Conclusions}

The results of the study indicated that: -The Waraos typical diet is associated to a low insulin resistance and the absence of dislipidemic behavior. This conclusion could project that a diet rich in complex carbohydrates, fibers and unsaturated fatty acids which are in great part supplied by the consumption of the Moriche palm fruit, unripe banana and "casabe" complemented with the ingestion of fish and exercise leads to prevention of metabolic syndrome. Even though they present a low HDL, they have low incidence of cardiovascular disease. -The Waraos, one of the oldest populations, have cultivated its customs through a good interrelationship with their habitat, and low incidence of metabolic syndrome and cardiovascular diseases that is a characteristic of a non-industrialized society. This allows demonstrating that the habitat and the man define the incidence of illnesses probably because of the relationship between habitat and genes.

\section{Acknowledgements}

Published as a paper based in a research conducted under the projects: NO PG 03-7607-2009-1, PG-09-6593-20062007 and PI 09-00-7035-2007 supported by Consejo de Desarrollo Científico y Humanístico (CDCH), Universidad Central de Venezuela.

\section{REFERENCES}

[1] I. Howard, J. Restrepo, J. Serra and L, Herrera, "Composition and Nutritive Value of Amazonian Palm Fruits," Food and Nutrition Bulletin, Vol. 21, No. 3, 2001, pp. 361-365.

[2] A. M. da C. Rodrigues, S. Darnet, L. H. M. da Silva, "Fatty Acid Profiles and Tocopherol Contents of Buriti (Mauritia flexuosa), Patawa (Oenocarpus bataua), Tucuma (Astrocaryum vulgare), Mari (Poraqueiba paraensis) and Inaja (Maximiliana maripa) Fruits," Journal of the Brazilian Chemical Society, Vol. 21, No. 10, 2010, pp. 2000-2004. doi:10.1590/S0103-50532010001000028

[3] C. S. Harcourt and J. A. Sayer, "The Conservation Atlas of Tropical Forests: The Americas," Simon and Schuster, New York, 1996, pp. 7-53.

[4] Venezuelan's Eco Regions, “Orinoco Delta Swamp Forests," 2011. http://ecoalliance.tripod.com/ecoregion-delta.htm

[5] C. Lubrano and J. R. Robin. "Major Compounds Study in Fruit Pulp Oils of Six Guiana Palms Species," Acta Botanica Gallica, Vol. 144, No. 4, 1997, pp. 495-499.

[6] O. Gibert, D. Dufour, A. Giraldo, T. Sánchez, M. Reynes, J.-P. Pain, A. González and A. Fernández, "Differentiation between Cooking Bananas and Dessert Bananas. 1. Morphological and Compositional Characterization of Cultivated Colombian Musaceae (Musa sp.) in Relation 
to Consumer Preferences," Journal of Agricultural and Food Chemistry, Vol. 57, No. 17, 2009, pp. 7857-7869. doi:10.1021/if901788x

[7] H. N. Englyst and J. H. Cummings, "Digestion of the Carbohydrates of Banana (Musa paradisiacal sapientum) in the Human Small Intestine," The American Journal of Clinical Nutrition, Vol. 44, No. 1, 1986, pp. 42-50.

[8] D. J. A. Jenkins, V. Vuksan, C. W. C. Kendall, P. Würsch, R. Jeffcoat, S. Waring, C. C. Mehling, E, Vidgen, L. S. A. EAugustin and E. Wong, "Physiological Effects of Resistant Starches on Fecal Bulk, Short Chain Fatty Acids, Blood Lipids and Glycemic Index," Journal of the American College of Nutrition, Vol. 17, No. 6, 1998, pp. 609-616.

[9] H. G. M. Liljeberg, A. K. E. Akerberg and I. M. E. Björck, "Effect of the Glycemic Index and Content of Indigestible Carbohydrates of Cereal-Based Breakfast Meals on Glucose Tolerance at Lunch in Healthy Subjects," The American Journal of Clinical Nutrition, Vol. 69, No. 4, 1999, pp. 647-655.

[10] J. Tovar, I B. Jorck and N. G. Asp, "On the Nutritional Properties of Starch and Dietary Fiber in Cassava Bread Nutrition," Reports International, Vol. 39, No. 6, 1989, pp. 1237-1246.

[11] K. W. Heaton, "Cost 92 Metabolic and Physiological Aspects of Dietary Fiber in Food-Recent Progress in the Analysis of Dietary Fibre," Proceeding of a Workshop, Copenhagen, 28-29 October 1994, pp. 15-39.

[12] F. W. Howard, "The Animal Class Insect and the Plant Family Palmae," In: F. W. Howard, D. Moore, R. M. Giblin-Davis and R. G. Abad, Eds., Insects on Palms, CABI, New York, pp. 1-32. doi:10.1079/9780851993263.0001

[13] M. Grayson, "Nutrigenomics," Nature, Vol. 468, No. 7327, 2010, p. S1. doi:10.1038/468S1a

[14] JNC7, "The Seventh Report of the Joint National Committee on Prevention, Detection, Evaluation and Treatment of High Blood Pressures," NIH Bethesda, MD, EEUU, 2003, p. 87.

[15] M. Lares, J. Castro and O. Obregón, "Determinación de la Sensibilidad Insulinica por el Modelo Matemático de Homeostásis Modelo Assessment (HOMA)". Sallus Militiae, Vol. 27, 2000, pp. 32 -34.

[16] K. Helrich, "Official Methods of Analysis of the A.O. A.C.," $15^{\text {th }}$ Edition, USA Association of Official Analytical Chemists, Washington, 2000.

[17] American Association of Cereal Chemist., "Approved methods of the American Association of Cereal Chemist." The American Association of Cereal Chemists, Minnesota, 2003.

[18] I. Goñi, L. Garcia, E. Mañas and F. Saura-Galixto, "Analysis of Resistant Starch: A Method for Foods and Food Products," Food Chemistry, Vol. 56, No. 4, 1996, pp. 445-449. doi:10.1016/0308-8146(95)00222-7

[19] Instituto Nacional de Nutrición, "Tabla de Composición de Alimentos para Uso Práctico," Instituto Nacional de Nutrición, Ministerio de Sanidad y Asistencia Social, Venezuela.

[20] R. P. Donahue, R. D. Abbotty, E. Bloom, D. M. Reed and K. Yano, "Central Obesity and Coronary Heart Disease in Men,” The Lancet, Vol. 329, No. 8537, 1987, pp. 821-824. doi:10.1016/S0140-6736(87)91605-9

[21] F. Zurlo, S. Lillioja, A. E.-D. Puente, B. L. Nyomba, I. Raz, M. F. Saad, et al., "Low Ratio of Fat to Carbohydrate, Oxidation as Predictor of Weight Gain: Study of 24-H RQ," American Journal of Physiology, Vol. 259, No. 5, 1990, pp. 650-657.

[22] C. Case, A. Palma, S. Brito, M. Lares and E. Pérez, "Factores de Riesgo Asociado a Diabetes Mellitus Tipo 2 en Indios Waraoss, Venezuela," Interciencia, Vol. 31, No. 4, 2006, pp. 309-311.

[23] Comité de Expertos de la OMS Sobre el Estado Físico, "El Estado FíSICO: Uso e Interpretación de la Antropometría," Serie de Informes Técnicos, Vol. 854, 1995. http://www.who.int/childgrowth/publications/physical_st atus_es/en/index.html

[24] Comité de Expertos de la OMS Sobre la Obesidad, "Obesity: Preventing and Managing the Global Epidemic," Report of a WHO Consultation on Obesity, WHO Technical Report Series, 2000.

[25] A. Blanco-Metzler, J. Tovar and M. Fernández-Piedra, "Caracterización Nutricional de los Carbohidratos y Composición Centesimal de Raíces y Tubérculos Tropicales Cocidos, Cultivados en Costa Rica," Archivos Latinoame-Ricanos de Nutrición, Vol. 54, No. 3, 2004, pp. 322-327.

[26] C. Case, M. Lares, E. Pérez, A. Palma, S. Brito and M. Schroeder, "Blood Glucose and Serum Lipid Levels in the Venezuelan Waraos Tribe: Possible Relationship with Moriche Fruit (Mauritia flexousa) Intake," Nutrition Metabolism \& Cardiovasculr Diseases, Vol. 17, No. 1, 2007, pp. 1-2.

[27] D. Liese, X. Hans-Werner, H. Bernner, H. Lowel, and U. Keil, "Assessing the Impact of Classical Risk Factors on Myocardial Infarction by Rate Advancement Periods," Journal of Epidemiology, Vol. 152, No. 9, 2000, pp. 884888. doi:10.1093/aje/152.9.884

[28] D. M. Hegsted, L. M. Ausman, J. A. Johnson and G. E. Dallal, "Dietary Fat and Serum Lipids: an Evaluation of the Experimental Data," The American Journal of Clinical Nutrition, Vol. 57, 1993, pp. 875-883.

[29] J. Dyerberg, H. O. Bang, E. Stoffersen, S. Moncada and J. R. Vane, "Eicosapentaenoic Acid and Prevention of Thrombosis and Atherosclerosis?" The Lance, Vol. 312, No. 8081, 1978, pp. 117-119. doi:10.1016/S0140-6736(78)91505-2

[30] I. Astiasarán, A. Martínez, "Alimentos Composición y Propiedades," McGraw-Hill-Interamericana de España, S. A. U. Primera Edición,Madrid, 2000.

[31] W. Coppens and B. Escalante, "Los Aborígenes de Venezuela," Fundación Las Salle, Monte Avila, Caracas, 
1988, pp. 585-689.

[32] ISOGG (International Society of Genetic Genealogy), "Árbol de Haplogrupos de ADN-Y 2010 de la International Society of Genetic Genealogy (ISOGG)," Y-DNA Haplogroup Tree 2011, Version. 6.53, 2011. http://www.isogg.org/tree/

[33] F. Ahmed, "Health: Edible advice," Nature Outlook, Vol. 468, No. 7327, 2010, pp S10-S12. doi: $10.1038 / 468 \mathrm{~S} 10 \mathrm{a}$

[34] P. Barter, A. M. Gotto, J. C. L. Rosa, J. Maroni, M. Szarek, S. M. Grudy, et al., "HDL Colesterol, Very Low Levels of LDL Colesterol and Cardiovascular Events," The New England Journal of Medicine, Vol. 357, 2007, pp. 13011310. doi:10.1056/NEJMoa064278

[35] S. Ragbir and J. Farmer, "Disfuncional High-Density
Lipoprotein and Atherosclerosis," Current Atherosclerosis Reports, Vol. 12, No. 5, 2010, pp. 343-348. doi:10.1007/s11883-010-0091-x

[36] A. E. Sumner, J. Zhou, A. Doumatey, O. E. Imoisili, A. Amoah, J. Acheampong, J. Oli, T. Johnson, C. Ade-Bamowo and C. N. Retiming, "Low HDL-Cholesterol with Normal Triglyceride Levels is the Most Common Lipid Pattern in West Africans and African Americans with Metabolic Syndrome: Implications for Cardiovascular Disease Prevention," CVD Prevention and Control, Vol. 5, No. 3, 2010, pp. 75-80. doi:10.1016/j.cvdpc.2010.07.003

[37] M. R. Akpa, D. Agomoah and D. D. Alasia, "Lipid Profile of Healthy Adult Nigerians in Port Harcourt, Nigeria," Nigeria Journal of Medicine, Vol. 15, No. 2, 2006, pp. 137-140. 